\title{
The cognitive impairment and risk factors of the older people living in high fluorosis areas: DKK1 need attention
}

Chao Ren ${ }^{1,2+}$, Peng Zhang ${ }^{1,3+}$, Xiao-Yan Yao ${ }^{2 \dagger}$, Hui-Hua Li ${ }^{4}$, Rui Chen ${ }^{5}$, Cai-Yi Zhang ${ }^{3 *}$ and De-Qin Geng ${ }^{1 *}$

\begin{abstract}
Objective: To evaluate cognitive impairment and risk factors of elders in high fluoride drinking water areas and investigate whether DKK1 is involved in this disorder.

Methods: MoCA-B and AD-8 were used to measure the cognitive functions of 272 and 172 subjects over the age of 60 came from the high and normal fluoride drinking water areas respectively, general information and peripheral blood were collected, the level of SOD, GSH and MDA were measured, mRNA level of DKK1, the concentration of blood fluoride and the polymorphism of APOE were tested.

Results: The blood fluoride concentration, mRNA level of DKK1 and ratio of abnormal cognitive function of subjects in high fluorine drinking water areas were higher than those in normal areas. The level of SOD of subjects in high fluorine drinking water was low compared with those in normal areas. The level of MDA and GSH had no difference between the two crowds in different fluorine drinking water areas. There were differences in cigarette smoking, education, dental status, hypertension, hyperlipidaemia and APOE results between the two crowds in different fluorine drinking water areas. The mRNA level of DKK1 and the level of cognitive function showed a positive correlation and DKK1 was one of five risk factors involved in cognitive impairment of older people living in high fluorosis areas.
\end{abstract}

Conclusions: The cognitive functions could be impaired in the older people living in high fluoride drinking water areas, and DKK1 may as a potential intervention point of this brain damage process need attention.

Keywords: Cognition, DKK1, Fluoride, Drinking water, Risk factors

\section{Introduction}

Fluoride can easily be found in our daily life, and humans may suffer from damage induced by fluorosis [1-3]. Some reports have suggested that excessive fluoride can cause impairments in many systems of the human body. Dental fluorosis and bone damage can easily occur. However,

\footnotetext{
*Correspondence: amanzcy@live.cn; gengdegintg@126.com

${ }^{\dagger}$ Chao Ren, Peng Zhang and Xiao-Yan Yao contributed equally to this work.

${ }^{1}$ Department of Neurology, The Affiliated Hospital of Xuzhou Medical University, Xuzhou 221006, China

${ }^{3}$ Department of Psychiatry and Psychology, The Affiliated Xuzhou Oriental Hospital of Xuzhou Medical University, Xuzhou 221000, China Full list of author information is available at the end of the article
}

it takes a longer time for side effects related to fluoride to manifest in the central nervous system. Fluoride exposure can affect emotions and cognition in animal models and in children during development [4-6]. One study reported that the intelligence quotient (IQ) and executive functions were lower in individuals living in high fluoride drinking water areas [7]. In our previous study, we found that cognitive disorders resulted from drinking water with high fluoride levels in rat model [8]. The specific mechanism of fluorosis in cognitive disorders was unclear, but some studies showed that oxidative stress damages, neuron apoptosis, changes in neurotransmitters, and synaptic dysfunctions are involved [9-11]. It 
suggested that oxidative stress damages deserve attention, for the fragmentation and redistribution of mitochondria and the imbalance between the mitochondrial fusion and fission were found in the neurons of the rat exposure to chronic fluoride. Under this circumstance, the respiratory electron transport chain was disturbed and more superoxide radicals were produced. These changes will result in the high level of oxidative stress and contribute to the brain injury [12]. For instance, we found that the antioxidant substance such as superoxide dismutase (SOD) and glutathione (GSH) decreased significantly in rat model of fluorosis in our previous study [8]. It indicated the linkage between cognitive impairment induced by fluoride and oxidative stress.

Recent studies have indicated that cognitive dysfunction is related to many different cell signaling pathways. One study reported that the canonical Wnt signalling pathway was involved in the development of Alzheimer's disease (AD) [13]. The Wnt signalling pathway plays an important role in neurogenesis, neuroplasticity, memory and learning, which may be potential mechanisms for cognitive impairments [14-16]. Dickkopf-1 (DKK1), a canonical Wnt signalling pathway inhibitor, may bind to and sequester LRP5/6 and then disrupt Wnt- FrizzledLRP6 complex formation, which would cause changes in down-stream pathway activities [17]. Our research team have recently demonstrated that the canonical Wnt pathway was involved in the fluoride-induced impairment of PC-12 cells [18] and BV2 cells [19], and we found the expression level of DKK1 was significantly higher in the fluoride group than that in control group. Excitingly, more and more studies proved DKK1 expression level increased significantly in the cerebrospinal fluid, plasma and brain tissue of $\mathrm{AD}$ patients and $\mathrm{AD}$ transgenic mice $[20,21]$. In our recent review, we supposed DKK1 may be a key mediator and potential risk factor for AD development, and it may also be as a novel intervention point of brain damage prevention that need attention [22].

Some reports suggested the cognition was impaired in high fluoride drinking water areas [23, 24]. However, the difference of risk factors of cognitive impairment between induced by fluorosis and $\mathrm{AD}$ in older people were not clear, not to speak of whether DKK1 is involved in this disorder (cognitive impairment induced by fluoride). Based on these, we investigated the cognitive level of older people and the related risk factors in the high fluoride drinking water areas in China. In brief, our aim was to investigate the risk factors for cognitive disorders induced by high fluoride drinking water and the relationship between cognitive function and the expression of DKK1.

\section{Methods and materials}

\section{Study design and sample size}

The study was carried out with an observational crosssectional survey design and performed from 1-Jan-2016 to 28-Feb-2017. The sample size was calculated by the PASS software. The calculation formula is below:

$$
\begin{aligned}
& \mathrm{n}=\frac{2 \bar{p} \bar{q}\left(Z_{\alpha}+Z_{\beta}\right)^{2}}{(P 1-P 2)^{2} .} \\
& \mathrm{P} 1=0.2, \quad \mathrm{P} 2=0.4, \quad \alpha=0.05, \quad \mathrm{Z}_{0.05}=1.96, \quad \beta=0.9, \\
& \mathrm{Z}_{\beta}=1.28, \mathrm{n}_{\min }=110 .
\end{aligned}
$$

\section{Study of subjects}

The fluoride concentration of drinking water was high in the Feng County, Xuzhou City, Jiangsu Province, China, where dental fluorosis was very common. However, there was no data available regarding the cognitive function of the individuals who lived in this area. In this study, a total of 272 subjects from the high fluoride drinking water community (water fluoride concentration $>2 \mathrm{mg} / \mathrm{L}$ ) of Feng County, Xuzhou City, Jiangsu Province, China, were randomly enrolled in this study. And a total of 172 subjects, from the normal fluoride drinking water community (water fluoride concentration $<0.8 \mathrm{mg} / \mathrm{L}$ ) of Suining County, Xuzhou City, Jiangsu Province, China, were randomly chosen as the control group. These two counties have a similar culture, lifestyle and economic development level. Individuals with cerebral ischaemia, brain tumours and psychiatric disorders were excluded. This study was approved by the Ethics Committee of Affiliated Xuzhou Oriental Hospital of Xuzhou Medical University, China.

\section{General information}

Socio-demographic and personal information was collected from each subject. These data included gender, age, education, alcohol drinking, smoking, dental status, hypertension, hyperlipidaemia, diabetes and family history (psychiatric diseases or dementia). Age was categorized into 3 groups as follows: 60-69years of age, $70-80$ years of age and older than 80 years of age. Education was categorized into the following groups: illiterate, primary school, middle school, and high school or higher. Dental status was categorized as follows: dental fluorosis, normal and dentures.

\section{Cognitive function tests}

The Montreal Cognitive Assessment-Basic (MoCA-B) and $\mathrm{AD}-8$ were used to investigate the cognitive functions of the subjects. The MoCA-B had excellent validity in screening for mild cognitive impairment in poorly 
educated older adults regardless of literacy [25]. The AD-8 is an 8-item informant-based questionnaire, which was designed to detect changes in the fields of memory, orientation, judgement and executive function [26].

\section{Blood sampling and pretreatment}

A total of 4 tubes of venous blood $(5 \mathrm{ml}$ each) were collected and centrifuged at $5000 \mathrm{rpm} / \mathrm{min}$ for $5 \mathrm{~min}$. Sera were stored at $-80^{\circ} \mathrm{C}$. These samples were used for testing the mRNA level of DKK1, fluoride concentration, SOD, GSH, malondialdehyde (MDA) concentration and apolipoprotein E (APOE) gene polymorphism.

\section{Biochemical tests}

Blood fluoride concentration was measured using the method of fluoride ion selective electrode method. Briefly, different concentrations of Fluoride Standard Liquid reagent were used to make a standard line, and then the concentration of the blood samples was adjusted according to the standard line.

The different oxidative stress status was evaluated by measuring levels of SOD, GSH and MDA according to the manufacturer's instructions in the reagent kit (Nanjing, Jiancheng, China).

The mRNA level of DKK1 was measured using qRTPCR. Briefly, total human blood RNA was isolated with Trizol reagent (ProbeGene, China), and the concentration was measured using ultraviolet spectrophotometry. Reverse transcription was achieved using the cDNA Synthesis Kit (ProbeGene, China), and qRT-PCR amplification was performed using the SYBR-Green Master mix (Probegene MQ051, China) with the following amplification conditions: $95^{\circ} \mathrm{C}$ for $10 \mathrm{~min}, 40$ cycles of $95^{\circ} \mathrm{C}$ for $15 \mathrm{~s}, 60^{\circ} \mathrm{C}$ for $30 \mathrm{~s}$, and $72^{\circ} \mathrm{C}$ for $2 \mathrm{~min}$. The amplification primer sequences were $\mathrm{F}: 5^{\prime}$ - TCA TAG CAC CTT GGA TGG GTA TTC - $3^{\prime}$, and R: $5^{\prime}$ - TTG GAC CAG AAG TGT CTA GCA CAA - $3^{\prime}$. The results were analysed using the ABI2720 PCR System (Applied Bio-systems, USA).

For analysis of APOE gene polymorphisms (also known as genotype), genomic DNA was extracted from collected venous blood samples using a commercial kit (QIAamp DNA Blood Mini Kit, Qiagen, Shanghai, China) beforehand. Then, the potentially mutated positions in 112 (rs429358) and 158 (rs7412) of the APOE gene were conducted by a detection kit (GeneChip Assay, Sinochip, Zhuhai, China) based on genomic DNA. First, all samples were amplified with the Verti ${ }^{\mathrm{TM}}$ DX Thermal Cycler (Life Technologies, Singapore) ( 45 cycles, $94^{\circ} \mathrm{C}$ for $30 \mathrm{~s}$ and $65^{\circ} \mathrm{C}$ for $45 \mathrm{~s}$ ); then the amplified products were assayed by the fully automated GeneChip detection system (Sinochip, Zhuhai, China). All genotyping results were obtained from the GeneChip automated analysis system.

\section{Statistical analysis}

Socio-demographic factors and numeration data were analysed using the chi-square $\left(\mathrm{X}^{2}\right)$ test. The nonparametric rank sum test was used to compare the quantitative data between two groups. The degree of association between fluorideinduced cognitive impairment and risk factors was analysed using binary logistic regression analysis. Bivariate correlation analysis was performed using Spearman correlation analysis. SSPS16.0 software was used to analyse all data. A $p$-level of 0.05 was considered statistically significant.

\section{Results \\ Demographic characteristics of subjects in the normal fluoride group and high fluoride group}

The demographic characteristics of subjects are displayed in Table 1 . The majority of subjects are female $(N=119$, $69.2 \%$ VS $N=166,61 \%$ in the two areas, respectively). Over $70 \%(N=122)$ of the subjects did not receive education in normal drinking area. The rate of fluorosis teeth $(N=266,97 \%)$, hypertension $(N=103,37.7 \%)$ and hyperlipemia $(N=34,12.5 \%)$ are higher in the participants who lived in the high fluoride drinking area than these who lived in the normal fluoride drinking area.

\section{The blood fluoride concentration in subjects from normal and high fluoride drinking water areas}

The blood fluoride concentration of subjects was higher in the high fluoride drinking water areas [0.04 (0.027$0.049) \mathrm{mg} / \mathrm{L}$ ] compared with the fluoride concentration in subjects from the normal fluoride drinking water areas [0.02 (0.016-0.029) mg/L] (Fig. 1).

\section{Associations between fluoride and oxidative stress}

The level of SOD, an anti-oxidative factor, increased significantly in subjects from the high fluoride water drinking areas [60.66(50.73-70.62) $\mathrm{U} / \mathrm{mL}]$ (Fig. 2A). The level of MDA, a pro-oxidative factor, and GSH, another anti-oxidative factor had no significant difference between the high and normal fluoride water drinking areas (Fig. 2B, C).

\section{Fluoride increased the mRNA level of DKK1}

DKK1 is an inhibitor of the canonical Wnt signalling pathway and is often associated with different diseases. Our previous studies (cellular and animal models) indicated that there was some relationship between DKK1 and fluoride. In this study, we measured the mRNA level of DKK1 by qRT-PCR. The mRNA level of DKK1 was significantly higher in subjects form the high fluoride drinking water areas [24.47(23.19-25.47)] than those from normal fluoride drinking water areas [22.05(20.99-23.24)] (Fig. 3). 
Table 1 The socio-demographic characteristics of subjects

\begin{tabular}{|c|c|c|c|c|}
\hline & Normal Fluoride Group & High Fluoride Group & $x^{2}$ & $p$ \\
\hline \multicolumn{5}{|l|}{ General information } \\
\hline Gender & 172 & 272 & 3.050 & 0.081 \\
\hline Male & $53(30.8 \%)$ & 106(39\%) & & \\
\hline Female & 119(69.2\%) & 166(61\%) & & \\
\hline Age (years) & & & 1.118 & 0.572 \\
\hline 60-69 & $84(48.8 \%)$ & $132(48.5 \%)$ & & \\
\hline $70-79$ & $73(42.4 \%)$ & 108(39.7\%) & & \\
\hline$\geq 80$ & $15(8.7 \%)$ & $32(11.8 \%)$ & & \\
\hline Education & & & 24.765 & $0.000^{*}$ \\
\hline Illiterate & $122(70.9 \%)$ & $137(50.4 \%)$ & & \\
\hline Primary school & $31(18 \%)$ & $88(32.4 \%)$ & & \\
\hline Middle school & $13(7.6 \%)$ & $44(16.2 \%)$ & & \\
\hline High Middle school and higher & $6(3.5 \%)$ & $3(1.1 \%)$ & & \\
\hline \multicolumn{5}{|l|}{ Risk factors } \\
\hline Cigarette smoking & & & 6.938 & $0.008^{* *}$ \\
\hline Yes & $14(8.1 \%)$ & $46(16.9 \%)$ & & \\
\hline No & 158(91.9\%) & $226(83.1 \%)$ & & \\
\hline Alcohol consumption & & & - & 0.43 \\
\hline Yes & $0(0 \%)$ & $1(0.4 \%)$ & & \\
\hline No & $172(100 \%)$ & $271(99.6 \%)$ & & \\
\hline \multicolumn{5}{|l|}{ Chronic diseases } \\
\hline Hypertension & & & 4.658 & $0.031^{*}$ \\
\hline Yes & $48(27.9 \%)$ & 103(37.9\%) & & \\
\hline No & $124(72.1 \%)$ & $169(62.1 \%)$ & & \\
\hline Hyperlipemia & & & 10.439 & $0.001^{*}$ \\
\hline Yes & $6(3.5 \%)$ & $34(12.5 \%)$ & & \\
\hline No & $166(96.5 \%)$ & $238(87.5 \%)$ & & \\
\hline Hyperglycemia & & & 0.092 & 0.761 \\
\hline Yes & $14(8.1 \%)$ & $20(7.4 \%)$ & & \\
\hline No & 158(91.9\%) & $252(92.6 \%)$ & & \\
\hline \multicolumn{5}{|l|}{ APOE gene polymorphisms } \\
\hline Genotype & & & 71.753 & $0.000^{* *}$ \\
\hline E2/E2 & $1(0.6 \%)$ & $1(0.4 \%)$ & & \\
\hline E2/E3 & $28(16.3 \%)$ & $139(51.5 \%)$ & & \\
\hline E2/E4 & $0(0 \%))$ & $4(1.5 \%)$ & & \\
\hline E3/E3 & 143(83.1\%) & $123(45.2 \%)$ & & \\
\hline E3/E4 & $0(0 \%)$ & $5(1.8 \%)$ & & \\
\hline \multicolumn{5}{|l|}{ Physical sign of fluorosis } \\
\hline Teeth & & & 476.841 & $0.000^{*}$ \\
\hline Normal & 155(90.1\%) & $2(0.7 \%)$ & & \\
\hline Dental fluorosis & $9(5.2 \%)$ & $266(97.8 \%)$ & & \\
\hline Denture & $8(4.7 \%)$ & $4(1.5 \%)$ & & \\
\hline
\end{tabular}

$A P O E$ apolipoprotein $\mathrm{E}$

${ }^{*} P<0.05$

${ }^{* *} P<0.01$

The incidence of cognitive impairment in older people increased in high fluoride drinking water areas

The MoCA-B and AD- 8 were used to measure the cognitive function of subjects. The results suggested that the ratio of abnormal cognitive function of study population in high fluorine drinking water areas were higher $(N=124,45.6 \%)$ than those $(N=26,15.1 \%)$ in normal areas (Table 2). 


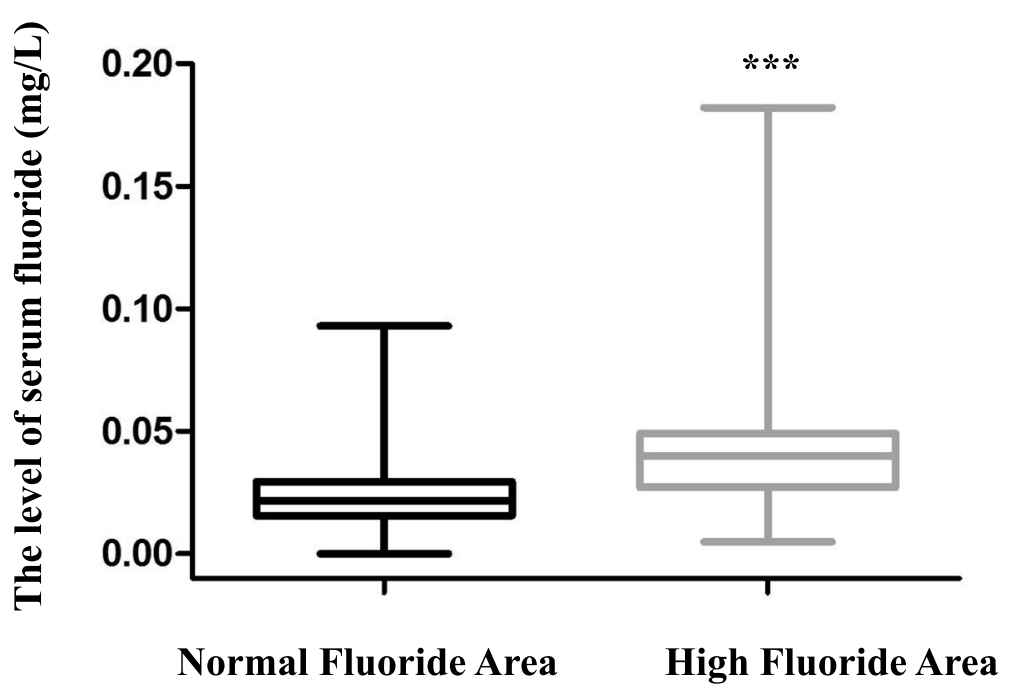

Fig. 1 The blood fluoride concentration in subjects from high and normal fluoride drinking water areas is shown. The blood fluoride concentration was higher in subjects form the high fluoride drinking water areas than those from normal fluoride drinking water areas. ${ }^{* *} P<0.001$

\section{The effect of education on cognitive function in subjects from different fluoride drinking water areas}

We investigated the effects of different levels of education on cognitive function in both groups. The incidence of cognitive impairment was higher in study population with illiterate $(N=52,38 \%)$ and primary school education level $(N=47,53.4 \%)$ who lived in the high fluoride drinking water area compared with those (illiterate $N=12,9.8 \%$, primary school $N=7,22.6 \%$ )from normal fluoride drinking water areas. However, the incidence of cognitive impairment in the study population with middle school $(N=4,30.8 \% ; N=24,54.5 \%)$ or high and over high middle school $(N=3,50 \% ; N=1,33 . \%)$ education level was not significantly different between the two groups (Table 3).

\section{Correlation coefficient}

In this study, spearman correlation analysis was used to investigate the relationship between some of observed variables (fluoride, DKK1 and MoCA-B). The result was showed in the Table 4 . There was a positive correlation ( $r=0.313$ ) between the level of DKK1 and the concentration of fluoride $(r=0.313, p<0.05)$, and MoCA-B $(r=0.320, p<0.05)$.

\section{Risk factors}

Risk factors of cognitive impairment were analysed using binary logistic regression analysis. As showed in Table 5, age, education, fluoride, DKK1 and dental fluorosis may be the risk factors of cognitive impairment in older people who lived in high fluorosis areas.

\section{Discussion}

Fluoride is a necessary element for the development and growth of organs in the human body, and it is often found in our environment [27, 28]. Frequently fluoride is added to toothpaste for the prevention of tooth decay. Since the 1980s, the use of fluoride in dental products has increased significantly. Furthermore, drinking water is a main source of fluoride, and the concentration of fluoride ranges from $0.1-0.8 \mathrm{mg} / \mathrm{L}$ [29]. However, the safety margin of fluoride is very narrow. Therefore, it is easy to suffer from fluorosis in high fluoride drinking water areas. The problems of high fluoride drinking water associated with dental and bone fluorosis had frequently been reported. Recently, some reports suggested that the excessive intake of fluoride could induce cognitive impairment in a rat model and in individuals who live in high fluoride drinking water areas [24]. Children who

(See figure on next page.)

Fig. 2 The level of SOD, MDA and GSH in subjects from high and normal fluoride drinking water areas: A The level of SOD, B The level of MDA, C The level of GSH. The level of SOD decreased significantly in the high fluoride drinking water areas. The level of MDA and GSH had no significant difference between the high and normal fluoride water drinking areas. ${ }^{* *} P<0.001$. GSH: glutathione, MDA: malondialdehyde, SOD: superoxide dismutase 
A

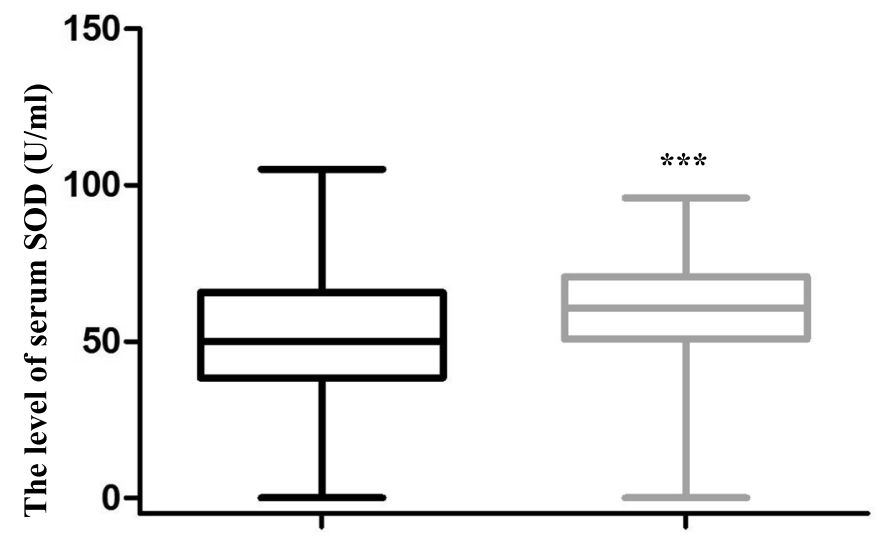

Normal Fluoride Area

High Fluoride Area

B

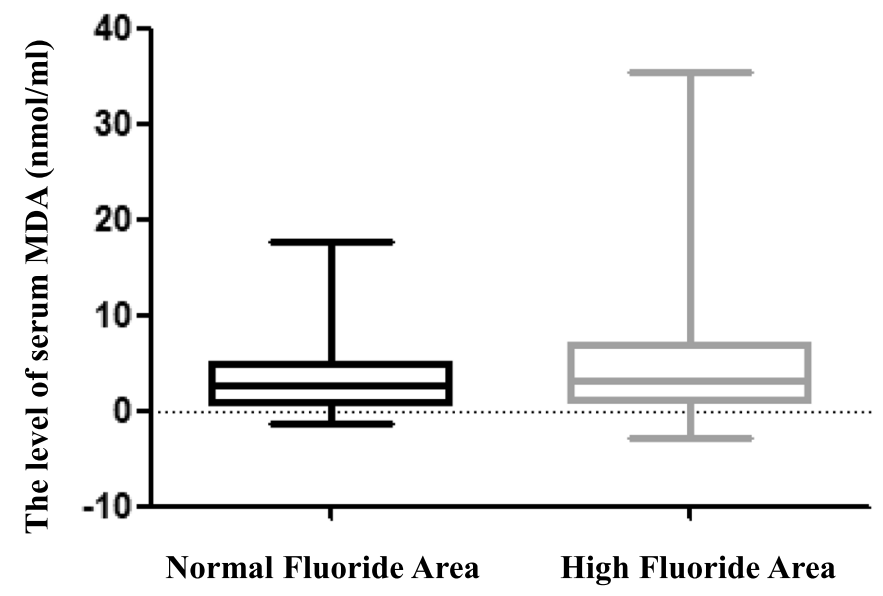

C

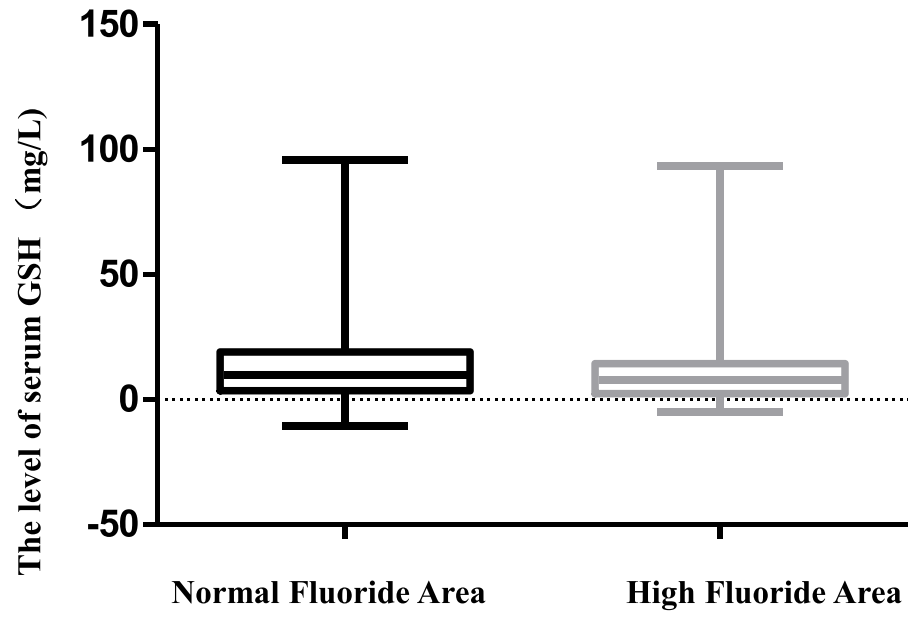

Fig. 2 (See legend on previous page.) 


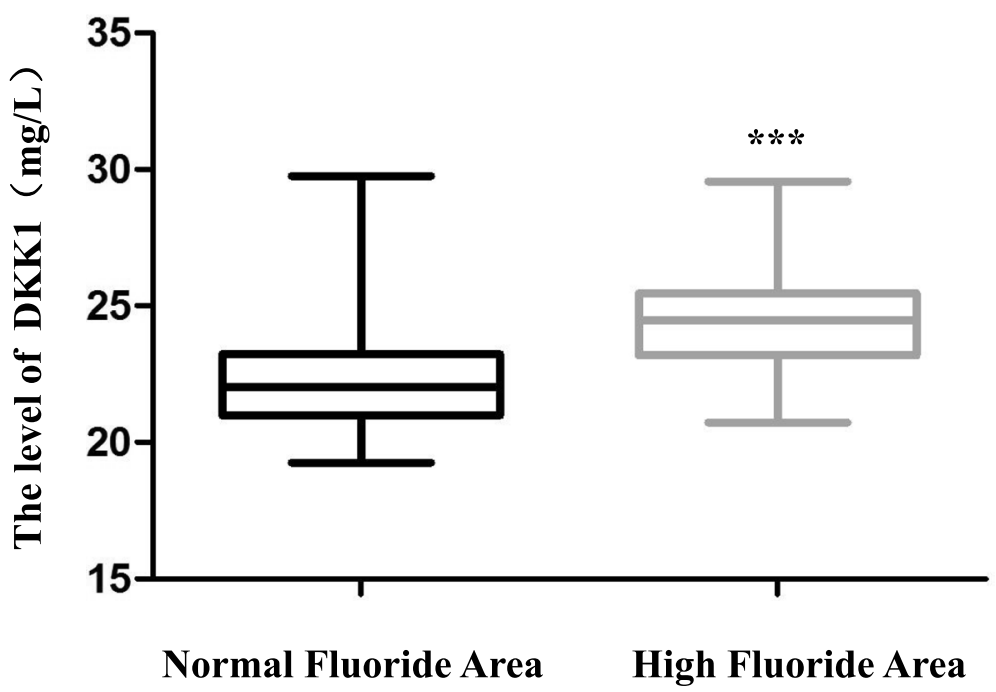

Fig. 3 The mRNA level of DKK1 in the high and low fluoride drinking water groups is shown. The mRNA level of DKK1 was higher in subjects form the high fluoride drinking water areas than those from normal fluoride drinking water areas. ${ }^{* * *} P<0.001$. DKK1: dickkopf-1

Table 2 Statistical analysis of the incidence of cognitive impairment measured by the AD-8 and MoCA-B

\begin{tabular}{|c|c|c|c|c|c|}
\hline & & $\mathrm{AD}-8 / \mathrm{MoC}$ & & & \\
\hline & & Normal & Abnormal & Total & \\
\hline Group & Normal & 146 (84.9\%) & $26(15.1 \%)$ & $172(100 \%)$ & \\
\hline & & & & & $X^{2}=43.736$ \\
\hline & Fluoride & $148(54.4 \%)$ & $124(45.6 \%)$ & $272(100 \%)$ & $P=0.000^{* *}$ \\
\hline Total & & $294(66.2 \%)$ & 150(33.8\%) & $444(100 \%)$ & \\
\hline
\end{tabular}

$A D-8$ Alzheimer's Disease-8, MoCA-B Montreal Cognitive Assessment-Basic ${ }^{* *} P<0.01$

were exposed to high fluoride drinking water in China and India showed decreases in IQ [5, 30].

General information is shown in Table 1. As shown in Table 1, differences in the level of education, hypertension, and APOE polymorphism were observed between the fluoride group and the control group. The blood fluoride concentration was tested and found to be higher in subjects from high drinking water areas than in subjects from normal drinking water areas, as shown in Fig. 1. However, toxic blood fluoride concentrations were not detected, which means that even in high fluoride drinking water areas, the blood fluoride concentrations in older people were considered safe. That may be the reason that the cognitive impairment induced by fluoride was not serious. Since a previous study showed that fluoride $(700 \mu \mathrm{mol} / \mathrm{L} \mathrm{NaF})$ could stimulate the ability of cellular anti- oxidative effects [31]. Therefore, it could be inferred that a certain low dose of fluoride exposure may play a protective rather than adverse role on cognitive
Table 3 The effect of level of education on cognitive impairment in subjects from different fluoride drinking water areas

\begin{tabular}{|c|c|c|c|}
\hline \multirow[t]{2}{*}{ Education } & \multicolumn{3}{|c|}{ AD-8/MoCA-B } \\
\hline & Normal & Abnormal & Statistical indicators \\
\hline \multicolumn{4}{|l|}{ Illiterate } \\
\hline Control Group & $110(90.2 \%)$ & $12(9.8 \%)$ & $x^{2}=27.428$ \\
\hline Fluoride Group & $85(62 \%)$ & $52(38 \%)$ & $P=0.000^{* *}$ \\
\hline \multicolumn{4}{|l|}{ Primary school } \\
\hline Control Group & $24(77.4 \%)$ & $7(22.6 \%)$ & $X^{2}=8.79$ \\
\hline Fluoride Group & $41(46.6 \%)$ & $47(53.4 \%)$ & $P=0.003^{* *}$ \\
\hline \multicolumn{4}{|l|}{ Middle school } \\
\hline Control Group & $9(69.2 \%)$ & $4(30.8 \%)$ & $x^{2}=1.418$ \\
\hline Fluoride Group & $20(45.5 \%)$ & $24(54.5 \%)$ & $P=0.234$ \\
\hline \multicolumn{4}{|c|}{ High Middle school and higher } \\
\hline Control Group & $3(50 \%)$ & $3(50 \%)$ & - \\
\hline Fluoride Group & $2(66.7 \%)$ & $1(33.3 \%)$ & $P=1.000$ \\
\hline
\end{tabular}

$A D-8$ Alzheimer's Disease-8, MoCA-B Montreal Cognitive Assessment-Basic ${ }^{* *} P<0.01$

Table 4 A correlation of matrix of DKK1, blood concentration of Fluoride and MoCA-B

\begin{tabular}{llll}
\hline Variables & Fluroide & DKK1 & MoCA-B \\
\hline Fluroide & 1 & & \\
DKK1 & 0.313 & 1 & 1 \\
MoCA-B & 0.320 & 0.365 & \\
\hline
\end{tabular}

DKK1 dickkopf-1, MoCA-B Montreal Cognitive Assessment-Basic 
Table 5 The risk factors of cognitive impairment were analyzed by regression logistics analysis

\begin{tabular}{|c|c|c|c|c|c|c|c|c|}
\hline \multicolumn{9}{|l|}{ Variables in the Equation } \\
\hline & \multirow[t]{2}{*}{ B } & \multirow[t]{2}{*}{ S.E. } & \multirow[t]{2}{*}{ Wald } & \multirow[t]{2}{*}{ df } & \multirow[t]{2}{*}{ Sig. } & \multirow[t]{2}{*}{$\operatorname{Exp}(B)$} & \multicolumn{2}{|c|}{ 95.0\% C.I.for EXP(B) } \\
\hline & & & & & & & Lower & Upper \\
\hline \multicolumn{9}{|l|}{ Step 1a } \\
\hline Group & 0.646 & 0.677 & 0.91 & 1 & 0.34 & 1.908 & 0.506 & 7.188 \\
\hline Gender & 0.381 & 0.376 & 1.026 & 1 & 0.311 & 1.464 & 0.7 & 3.06 \\
\hline Age & & & 14.678 & 2 & 0.001 & & & \\
\hline Age (1) & 0.765 & 0.264 & 8.42 & 1 & 0.004 & 2.15 & 1.282 & 3.606 \\
\hline Age (2) & 1.41 & 0.417 & 11.432 & 1 & 0.001 & 4.094 & 1.808 & 9.268 \\
\hline Education & & & 16.02 & 3 & 0.001 & & & \\
\hline Education (1) & 1.035 & 0.325 & 10.145 & 1 & 0.001 & 2.815 & 1.489 & 5.322 \\
\hline Education (2) & 1.405 & 0.431 & 10.618 & 1 & 0.001 & 4.076 & 1.751 & 9.49 \\
\hline Education (3) & 2.015 & 0.884 & 5.202 & 1 & 0.023 & 7.502 & 1.328 & 42.389 \\
\hline Height & -0.004 & 0.022 & 0.037 & 1 & 0.848 & 0.996 & 0.954 & 1.039 \\
\hline Weight & -0.008 & 0.016 & 0.254 & 1 & 0.614 & 0.992 & 0.962 & 1.023 \\
\hline Fluoride & 20.047 & 6.604 & 9.215 & 1 & 0.002 & $5.08 \mathrm{E}+08$ & $1.22 \mathrm{E}+03$ & $2.12 \mathrm{E}+14$ \\
\hline DKK1 & 0.318 & 0.081 & 15.323 & 1 & 0.000 & 1.374 & 1.172 & 1.611 \\
\hline Cigarette smoking & 0.132 & 0.391 & 0.113 & 1 & 0.736 & 1.141 & 0.53 & 2.455 \\
\hline Alcohol consumption & -20.128 & $4.02 E+04$ & 0.000 & 1 & 1 & 0.000 & 0.000 & \\
\hline Dental fluorosis & & & 7.896 & 2 & 0.019 & & & \\
\hline Fluorosis (1) & 1.734 & 0.687 & 6.365 & 1 & 0.012 & 5.665 & 1.472 & 21.792 \\
\hline Fluorosis (2) & 1.683 & 0.787 & 4.58 & 1 & 0.032 & 5.384 & 1.152 & 25.153 \\
\hline Hypertension & -0.04 & 0.266 & 0.022 & 1 & 0.881 & 0.961 & 0.57 & 1.619 \\
\hline Hyperglycemia & 0.118 & 0.476 & 0.062 & 1 & 0.804 & 1.125 & 0.443 & 2.858 \\
\hline Hyperlipemia & -0.379 & 0.425 & 0.795 & 1 & 0.373 & 0.684 & 0.297 & 1.575 \\
\hline SOD & -0.009 & 0.008 & 1.422 & 1 & 0.233 & 0.991 & 0.975 & 1.006 \\
\hline GSH & 0.004 & 0.009 & 0.157 & 1 & 0.692 & 1.004 & 0.985 & 1.022 \\
\hline MDA & 0.014 & 0.025 & 0.343 & 1 & 0.558 & 1.014 & 0.967 & 1.065 \\
\hline APOE & & & 0.491 & 4 & 0.974 & & & \\
\hline APOE(1) & 20.42 & $2.67 E+04$ & 0 & 1 & 0.999 & $7.38 \mathrm{E}+08$ & 0 & \\
\hline APOE(2) & 20.36 & $2.67 \mathrm{E}+04$ & 0 & 1 & 0.999 & $6.96 \mathrm{E}+08$ & 0 & \\
\hline APOE(3) & 20.499 & $2.67 \mathrm{E}+04$ & 0 & 1 & 0.999 & $7.99 \mathrm{E}+08$ & 0 & \\
\hline $\operatorname{APOE}(4)$ & 21.105 & $2.67 E+04$ & 0 & 1 & 0.999 & $1.47 \mathrm{E}+09$ & 0 & \\
\hline Constant & 8.132 & $4.06 \mathrm{E}+04$ & 0 & 1 & 1 & $3.40 \mathrm{E}+03$ & & \\
\hline
\end{tabular}

\section{Notes}

1. The age variables in this study are calculated in comparison with the "60-69years old" group. The parameter of the Age (1) row gives the OR value and $P$ value to the "70-79years old" group relative to "60-69years old" group. The parameter of the Age (2) row gives the OR value and $P$ value to the " 80 years old and above" group relative to "60-69years old" group

2. The variables of education level in this study are calculated in comparison with the "illiterate" group. The parameter of the Education (1) row gives the OR value and $P$ value of the "primary school" group relative to "illiterate" group. The parameter of the Education (2) row gives the OR value and $P$ value to the "junior high school" group relative to "illiterate" group. The parameter of the Education (3) row gives the OR value and $P$ value to the "high school and above" group relative to "illiterate" group

3. The variables of dental fluorosis in this study are calculated in comparison with the "normal teeth" group. The parameter of the Fluorosis (1) row gives the OR value and $P$ value of the "dental fluorosis" group relative to "normal teeth" group. The parameter of the Fluorosis (2) row gives the OR value and $P$ value to the "all dentures (no teeth or false braces)" group relative to "normal teeth" group

4. The APOE variables in this study are calculated in comparison with "E2/E2" group. The parameter in APOE (1) row gives the OR value and P value to "E2/E3" group relative to "E2/E2" group". The parameter in APOE (2) row gives the OR value and P value to the "E2/E4" group relative to "E2/E2" group. The parameter in APOE (3) row gives the OR value and P value to the "E3/E3" group relative to "E2/E2" group. The parameter in APOE (4) row gives the OR value and P value to the "E3/E4" group relative to "E2/E2" group 
impairment through the mechanisms of stimulating cells viability and anti-oxidative ability [24]. Moreover, fluorosis was associated with some other factors including age, kidney function, and sex [32]. The results showed that the incidence of dentures was higher in subjects in the normal fluoride drinking water areas. Fluoride is often added to toothpaste for the prevention of cavities, although the absence of fluoride does not necessarily contribute to the development of cavities. Nevertheless, fluoride had a protective effect against damage to the teeth caused by acid.

Oxidative stress is very common in patients with cognitive impairment, as usual, anti-oxidative factors decreased and pro-oxidative factors increased significantly. In our previous study, damage associated with oxidative stress from fluorosis was observed in a rat model [8]. In the present study, we measured two factors related to the oxidative stress. The results indicated that the level of SOD increased significantly in subjects from high fluoride drinking water areas. There was no significant difference in the level of GSH and MDA between the two groups. This result was not completely consistent with the results of our previous animal experiment [8]. The reason may be that the higher concentration of fluoride (not a toxic concentration) stimulated the activation of the oxidative system, which led to an increase in the level of the anti-oxidative stress factor SOD. These findings could indicate that a protective and reactive mechanism was engaged in response to the increased blood fluoride concentration [31]. What's more, it further supported the viewpoint presented by $\mathrm{Li}$ et al. that the certain low doses of fluoride intake may be a potential protective rather than a harmful factor for cognitive function; however, high fluoride exposure is a potential risk factor for cognitive impairment in older population [24].

As shown in Tables 1 and 3, although the prevalence of subjects who were illiterate was lower in the high fluoride drinking water areas, the incidence of abnormal cognitive function was higher. This result suggested that fluoride could increase the incidence of cognitive impairment. Additionally, we found that less education was associated with a higher incidence of cognitive impairment. For subjects who received more than 8 years of education (above middle school in China), no significant difference in cognitive function was observed between subjects from high fluoride drinking water areas and those from normal fluoride drinking water areas. This finding possibly suggested that the severity of cognitive impairment induced by fluoride was less in person with the higher level of education. More and more researches suggest that people with more education have lower prevalence of dementia [33]. Some scholars believe that this is benefit from the high cognitive reserve in individuals with high education [34]. But this protective effect of a high-education level may only be stronger in the early stage of disease [35]. The older persons with cognitive impairment induced by fluorosis in our study may be in the early stages of the disease. Meanwhile, other studies have found that high education may offer protection against tauopathy in patients with mild cognitive impairment [36].

DKK1, an inhibitor of the canonical Wnt signalling pathway, has been reported to be involved in cognitive impairment [37]. Increased DKK1 is associated with $\mathrm{AD}$ [38]. A positive correlation exists between cognitive function and DKK1 expression in diabetic rats, and there is also a positive correlation between DKK1-reducing therapy and improved cognitive function in rats [39]. Our recent research found that the level of DKK1 increased significantly in PC-12 cells [18] and BV2 cells [19] exposed to fluoride. However, the expression level of DKK1 in older people from high fluoride drinking water areas is unknown. The mRNA level of DKK1 was measured in both groups. The level of DKK1 increased significantly in subjects from high fluoride drinking water areas compared with that in subjects from normal fluoride drinking water areas. And we also investigated the correlation between observed variability. The result implied that DKK1was correlated with cognition and Fluoride concentration, although the correlation was weak. This finding suggested that DKK1 could be an indicator of cognitive impairment induced by fluoride. The function of DKK1 in the process of this disorder is unknown. Scientifically, we also need to calmly consider few limitations in this study. Firstly, the samples were chosen from one province in China and more high fluoride drinking water areas should be involved in the future study. Secondly, we could not clear which specific aspect of the cognition, such as memory, language, calculations, orientation, attention and concentration, executive functions, visuoconstructional skills, and conceptual thinking, was affected by fluoride via the disfunction of DKK1 and more researches should be performed in the future.

\section{Conclusions}

In conclusion, cognitive impairment could be induced by high fluoride drinking water, and DKK1 may be involved in this process. However, the specific mechanisms are unclear. More studies are needed to determine the function of DKK1, which may as a potential intervention point of this brain damage process that need attention.

\section{Abbreviations}

AD: Alzheimer's Disease; APOE: Apolipoprotein E; DKK1: Dickkopf-1; GSH: Glutathione; IQ: Intelligence quotient; MDA: Malondialdehyde; MoCA-B: Montreal Cognitive Assessment-Basic; SOD: Superoxide dismutase. 


\section{Acknowledgments}

Thanks to all the staff and subjects who participated in the questionnaire.

\section{Authors' contributions}

CR implemented epidemiological investigation, found the references and drafted the manuscript. PZ and XYY read the literature, summarized the information and helped to draft the manuscript. $H H \mathrm{~L}$ and $\mathrm{RC}$ made data collation and analysis. RC and PZ drew the tables and Figs. CY Z and DQ G designed the study, modified the manuscript and guided the above work. All authors read and approved the final manuscript.

\section{Funding}

This study was supported by Natural Science Foundation of Jiangsu Province (BK20151159), Shandong Provincial Key Research \& Development Project (2017GSF218043), National Natural Science Foundation of China (81501185), Jiangsu Provincial Medical Youth Talent (QNRC2016369) and Xuzhou Medical Talents Project and Xuzhou technological and scientific project (KC14SH050),

\section{Availability of data and materials}

The datasets used or analysed during the current study are available from the corresponding author on reasonable request.

\section{Declarations}

\section{Ethics approval and consent to participate}

The study was granted ethical approval by the Affiliated Xuzhou Oriental Hospital of Xuzhou Medical University, and was performed in accordance with the guidelines of the Helsinki Declaration and the CIOMS's international ethical guidelines. The written informed consent was obtained from all the participants.

\section{Consent for publication}

Not applicable.

\section{Competing interests}

The authors declare that they have no competing interests.

\section{Author details}

'Department of Neurology, The Affiliated Hospital of Xuzhou Medical University, Xuzhou 221006, China. ${ }^{2}$ Department of Neurology, Department of Neurology Yantai Yuhuangding Hospitalof Qingdao University, Yantai 264000, China. ${ }^{3}$ Department of Psychiatry and Psychology, The Affiliated Xuzhou Oriental Hospital of Xuzhou Medical University, Xuzhou 221000, China. ${ }^{4}$ Zhenjiang Mental Health Center, The Fifth People's Hospital of Zhenjiang City, Zhenjiang 212000, China. ${ }^{5}$ Department of Neurology, The Affiliated Huai'an Hospital of Xuzhou Medical University, Huai'an 223002, China.

Received: 29 March 2021 Accepted: 25 November 2021 Published online: 09 December 2021

\section{References}

1. Archer NP, Napier TS, Villanacci JF. Fluoride exposure in public drinking water and childhood and adolescent osteosarcoma in Texas. Cancer Causes Control. 2016;27(7):863-8.

2. Karademir S, Akcam M, Kuybulu AE, et al. Effects of fluorosis on QT dispersion, heart rate variability and echocardiographic parameters in children. Anadolu Kardiyol Derg. 2011;11(2):150-5.

3. Wang W, Xu J, Liu K, et al. Suppression of Sclerostin and Dickkopf-1 levels in patients with fluorine bone injury. Environ Toxicol Pharmacol. 2013;35(3):402-7.

4. Bartos M, Gumilar F, Bras C, et al. Neurobehavioural effects of exposure to fluoride in the earliest stages of rat development. Physiol Behav. 2015; 147:205-12.

5. Choi AL, Zhang Y, Sun G, et al. Association of lifetime exposure to fluoride and cognitive functions in Chinese children: a pilot study. Neurotoxicol Teratol. 2015:47:96-101.

6. Liu F, Ma J, Zhang H, et al. Fluoride exposure during development affects both cognition and emotion in mice. Physiol Behav. 2014;124:1-7.
7. Choi AL, Sun G, Zhang Y, et al. Developmental fluoride neurotoxicity: a systematic review and Meta-analysis. Environ Health Perspect. 2012;120(10):1362-8.

8. Zhang C, Ren C, Chen H, et al. The analog ofGinkgo bilobaExtract 761 is a protective factor of cognitive impairment induced by chronic fluorosis. Biol Trace Elem Res. 2013;153(1-3):229-36

9. Pereira M, Dombrowski PA, Losso EM, et al. Memory impairment induced by sodium fluoride is associated with changes in brain monoamine levels. Neurotox Res. 2011;19(1):55-62.

10. Sun Z, Niu R, Wang B, et al. Fluoride-induced apoptosis and gene expression profiling in mice sperm in vivo. Arch Toxicol. 2011;85(11):1441-52.

11. Zhu W, Zhang J, Zhang Z. Effects of fluoride on synaptic membrane fluidity and PSD-95 expression level in rat Hippocampus. Biol Trace Elem Res. 2011;139(2):197-203.

12. Lou DD, Guan ZZ, Liu YJ, et al. The influence of chronic fluorosis on mitochondrial dynamics morphology and distribution in cortical neurons of the rat brain. Arch Toxicol. 2013;87(3):449-57.

13. Liu CC, Tsai CW, Deak F, et al. Deficiency in LRP6-mediated Wnt signaling contributes to synaptic abnormalities and amyloid pathology in Alzheimer's disease. Neuron. 2014;84(1):63-77.

14. Cerpa W, Gambrill A, Inestrosa NC, et al. Regulation of NMDA-receptor synaptic transmission by Wnt signaling. J Neurosci. 2016;31(26):9466-71.

15. Cerpa W, Godoy JA, Alfaro I, et al. Wnt-7a, modulates the synaptic vesicle cycle and synaptic transmission in hippocampal neurons. J Biol Chem. 2008;283(9):5918-27.

16. Pan $Y-Y$, Deng $Y$, Xie S, et al. AlteredWntSignalingPathwayinCognitivelmpairmentCausedbyChronicIntermittentHypoxia:FocusonGlycogenSyntha seKinase-3ßandß-catenin. Chin Med J. 2016;129(7):838-45.

17. Menezes ME, Devine DJ, Shevde LA, et al. Dickkopf1: a tumor suppressor or metastasis promoter? Int J Cancer. 2012;130(7):1477-83.

18. Zhang CY, Chen R, Wang F, et al. EGb-761 attenuates the anti-proliferative activity of fluoride via DDK1 in PC-12 cells. Neurochem Res. 2017:42(2):606-14

19. Chen $R$, Zhao LD, Liu H, et al. Fluoride induces Neuroinflammation and alters Wnt signaling pathway in BV2 microglial cells. Inflammation. 2017:40(4):1123-30

20. Caricasole A, Copani A, Aronica E, et al. Induction of Dickkopf-1, a negative modulator of the Wnt pathway, is associated with neuronal degeneration in Alzheimer's brain. J Neurosci. 2004;24(26):6021-7.

21. Rosi MC, Luccarini I, Grossi C, et al. Increased Dickkopf-1 expression in transgenic mouse models of neurodegenerative disease. J Neurochem. 2010;112(6):1539-51.

22. Ren C, Gu X, Li H, et al. The role of DKK1 in Alzheimer's disease: a potential intervention point of brain damage prevention? Pharmacol Res. 2019;144:331-5.

23. Ko K, Jung M, Hong S. Prevalence of cognitive impairment and related factors among the elderly in rural communities of Jeju Province. Taehan Kanho Hakhoe Chi. 2003;33(4):503-9.

24. Li M, Gao Y, Cui J, et al. Cognitive impairment and risk factors in elderly people living in fluorosis areas in China. Biol Trace Elem Res. 2016:172(1):53-60.

25. Julayanont P, Tangwongchai S, Hemrungrojn S, et al. The Montreal cognitive assessment-basic: a screening tool for mild cognitive impairment in illiterate and low-educated elderly adults. J Am Geriatr Soc. 2015:63(12):2550-4.

26. Galvin JE, Roe CM, Powlishta KK, et al. The AD8: a brief informant interview to detect dementia. Neurology. 2005;65(4):559-64.

27. Ando M, Tadano M, Asanuma $\mathrm{S}$, et al. Health effects of indoor fluoride pollution from coal burning in China. Environ Health Perspect. 1998;106(5):239-44.

28. Ersoy $I H$, Koroglu BK, Varol S, et al. Serum copper, zinc, and magnesium levels in patients with chronic fluorosis. Biol Trace Elem Res. 2011;143(2):619-24

29. Declan W, William $P$, Hardy $L$, et al. Risk assessment of fluoride intake from tea in the Republic of Ireland and its implications for public health and water fluoridation. Int J Environ Res Public Health. 2016;13(3):E259.

30. Sebastian ST, Sunitha S. A cross-sectional study to assess the intelligence quotient (IQ) of school going children aged 10-12 years in villages of Mysore district, India with different fluoride levels. J Indian Soc Pedod Prev Dent. 2015;33(4):307-11. 
31. Bian JC, Lin XY, Yang XX, et al. Human umbilical vein vascular endothelial cell injury induced by fluoride in vitro. China J Endemiol. 2011;30(2):142-7.

32. Krishnamachari KAVR. Skeletal fluorosis in humans: a review of recent progress in the understanding of the disease. Prog Food Nutr Sci. 1986;10(3-4):279-314.

33. Crimmins EM, Saito Y, Kim JK, et al. Educational Differences in the Prevalence of Dementia and Life Expectancy with Dementia: Changes from 2000 to 2010. J Gerontol B Psychol Sci Soc Sci. 2018:73(suppl_1):S20-8.

34. Rodriguez FS, Zheng L, Chui HC, et al. Psychometric characteristics of cognitive reserve: how high education might improve certain cognitive abilities in aging. Dement Geriatr Cogn Disord. 2019;47(4-6):335-44.

35. Rimkus CM, Avolio IMB, Miotto EC, et al. The protective effects of higheducation levels on cognition in different stages of multiple sclerosis. Mult Scler Relat Disord. 2018;22:41-8.

36. Rolstad S, Nordlund A, Eckerström C, et al. High education may offer protection against tauopathy in patients with mild cognitive impairment. J Alzheimers Dis. 2010;21(1):221-8.

37. Purro SA, Galli S, Salinas PC. Dysfunction of Wnt signaling and synaptic disassembly in neurodegenerative diseases. J Mol Cell Biol. 2014;6(1):75-80

38. Ortiz-Matamoros A, Salcedo-Tello P, Avila-Muñoz E, et al. Role of Wnt signaling in the control of adult hippocampal functioning in health and disease: therapeutic implications. Curr Neuropharmacol. 2013;11(5):465-76.

39. Shen ZX, Xiao Q, Zhao YX, et al. Effects of ghrelin on hippocampal DKK-1 expression and cognitive function in rats with diabetes mellitus. Nan Fang Yi Ke Da Xue Xue Bao. 2016;36(4):500-5 Article in Chinese.

\section{Publisher's Note}

Springer Nature remains neutral with regard to jurisdictional claims in published maps and institutional affiliations.

- fast, convenient online submission

- thorough peer review by experienced researchers in your field

- rapid publication on acceptance

- support for research data, including large and complex data types

- gold Open Access which fosters wider collaboration and increased citations

- maximum visibility for your research: over $100 \mathrm{M}$ website views per year

At BMC, research is always in progress.

Learn more biomedcentral.com/submissions 